Instrumental A chievemerts

\title{
Crystal Structure of Phenolphthalein
}

\author{
Hiromasa Sugiura*, Toshiyuki Kato*, Hitoshi SEnda*, Ko-Ki Kunimoto*†, \\ Akio KUWAE** and Kazuhiko HaNA ${ }^{* * * *}$ \\ *Department of Chemistry and Chemical Engineering, Faculty of Technology, Kanazawa University, \\ Kakuma-machi, Kanazawa 920-1192, Japan \\ **Institute of Natural Sciences, Nagoya City University, Nagoya 467-8501, Japan \\ ***Gifu Pharmaceutical University, Gifu 502-8585, Japan
}

We have studied the molecular structures of various organic dyes by the vibrational spectroscopies. ${ }^{1}$ Our recent research interests have been focused on the inclusion phenomena of the phthalein dyes in various organic hosts. As a part of our study, the X-ray analysis of 3,3-bis(4-hydroxyphenyl)-1(3H)-isobenzofuranone, better known as phenolphthalein, was undertaken. The $\mathrm{pH}$ dependent color change of phenolphthalein has been ascribed to a structure change from the lactone (I) to the dianionic resonating form (II), as shown in Fig. 1. Phenolphthalein shows vibrational bands characteristic of the structure (I) in the solid state. The $\mathrm{OH}$ stretching bands are observed at 3383, 3329 and $3291 \mathrm{~cm}^{-1}$ in the IR spectrum. The intense band at $1737 \mathrm{~cm}^{-1}$ with a shoulder peak at $1718 \mathrm{~cm}^{-1}$ is assigned to the $\mathrm{C}=\mathrm{O}$ stretching of the lactone group. The corresponding Raman bands are observed at 1737 and $1719 \mathrm{~cm}^{-1}$.

Crystals suitable for X-ray analysis were grown from an aqueous ethanol solution at room temperature. A colorless prism with dimensions $0.6 \times 0.3 \times 0.4 \mathrm{~mm}$ was mounted on a glass fiber. All measurements were made on a Rigaku AFC-5R diffractometer with a graphite monochromated Mo $\mathrm{K}_{\alpha}$ radiation $(\lambda=0.71069 \AA)$. The detailed measurement conditions and crystal data are listed in Table 1. The intensity data were collected at $23^{\circ} \mathrm{C}$ using the $\omega-2 \theta$ scan technique to a maximum $2 \theta$ of value of $55.0^{\circ}$. A total of 4195 reflections were collected. The intensities of three representative reflections which were measured after every 150 reflections declined by $0.49 \%$. A linear correction was applied to the data to account for this phenomenon. The linear absorption coefficient for Mo $\mathrm{K}_{\alpha}$ is $0.8 \mathrm{~cm}^{-1}$. An

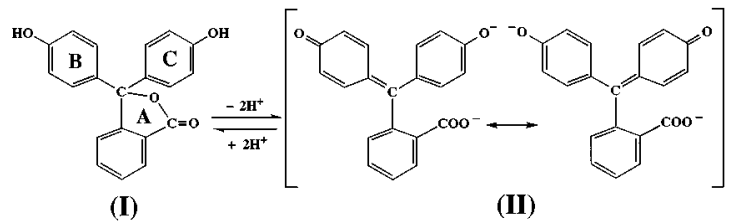

Fig. 1 Dissociation equilibrium of phenolphthalein

$\doteqdot$ To whom correspondence should be addressed. empirical absorption correction, based on azimuthal scans of several reflections, was applied, which resulted in transmission factors ranging from 0.98 to 1.00 . The data were corrected for Lorentz and polarization effects.

The structure was solved by direct methods. ${ }^{2}$ The non-hydrogen atoms were refined anisotropically. All hydrogen atoms were located from a difference Fourier map and included in the full-matrix least squares refinement. The atomic scattering factors and anomalous dispersion terms were taken from the International Tables for X-ray Crystallography, Vol. IV. ${ }^{3}$ All calculations were performed using the program TEXSAN crystallographic software package. ${ }^{2}$ Selected positional parameters are listed in Table 2. The molecular structure is shown in Fig. 2, together with the atomic labeling scheme. Selected bond distances and angles are listed in Table 3.

There are two independent molecules in the asymmetric unit (Molecule 1 and Molecule 2). The molecules consist essentially of three groups: an isobenzofu-

Table 1 Crystal and experimental data

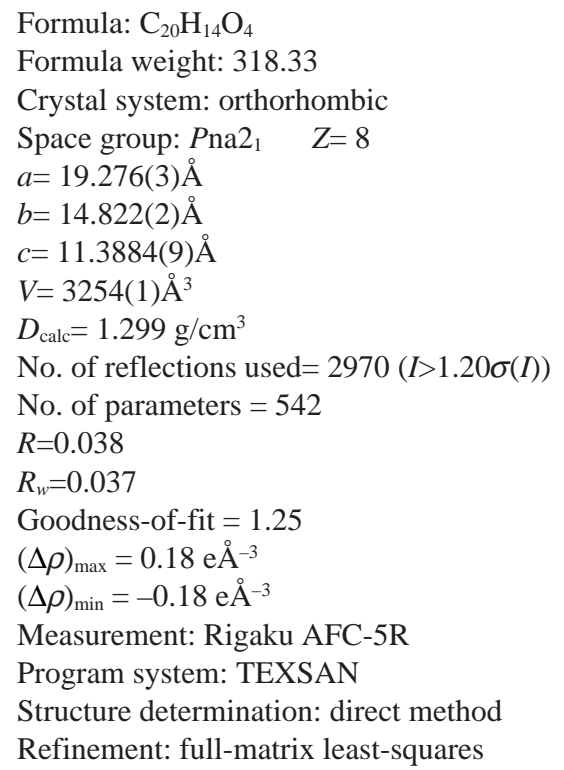


Table 2 Fractional coordinates and equivalent isotropic thermal parameters of non-hydrogen atoms

\begin{tabular}{|c|c|c|c|c|}
\hline Atom & $x$ & $y$ & $z$ & $B_{\text {eq }} / \AA^{2}$ \\
\hline O1 & $0.1304(1)$ & $0.4152(2)$ & 0.0982 & $4.2(1)$ \\
\hline $\mathrm{O} 2$ & $0.4595(1)$ & $-0.0192(2)$ & 0.4275 & $4.9(1)$ \\
\hline$O B$ & $0.3255(1)$ & $0.0906(1)$ & $-0.0469(2)$ & $3.4(1)$ \\
\hline O4 & $0.3494(1)$ & $0.0339(2)$ & -0.2235 & $5.7(1)$ \\
\hline O5 & $0.4450(1)$ & $0.4361(2)$ & $0.3963(3)$ & $4.7(1)$ \\
\hline 06 & $0.3495(1)$ & $0.4153(2)$ & $-0.4315(2)$ & $4.4(1)$ \\
\hline O7 & $0.2592(1)$ & $0.6303(1)$ & $0.0143(2)$ & $3.22(9)$ \\
\hline 08 & $0.1913(1)$ & $0.7456(2)$ & $0.0592(3)$ & $5.4(1)$ \\
\hline $\mathrm{C} 1$ & $0.3497(1)$ & $0.1644(2)$ & $0.0320(3)$ & $3.0(1)$ \\
\hline $\mathrm{C} 2$ & $0.2882(1)$ & $0.2268(2)$ & $0.0546(3)$ & $2.9(1)$ \\
\hline C3 & $0.2879(2)$ & $0.2832(2)$ & $0.1519(3)$ & $3.6(1)$ \\
\hline $\mathrm{C} 4$ & $0.2351(2)$ & $0.3456(2)$ & $0.1687(3)$ & $3.5(1)$ \\
\hline $\mathrm{C} 5$ & $0.1826(1)$ & $0.3527(2)$ & $0.0874(3)$ & $3.1(1)$ \\
\hline C6 & $0.1818(2)$ & $0.2969(2)$ & $-0.0094(4)$ & $3.8(1)$ \\
\hline C7 & $0.2343(2)$ & $0.2350(2)$ & $-0.0253(3)$ & $3.5(1)$ \\
\hline $\mathrm{C} 8$ & $0.3794(1)$ & $0.1191(2)$ & $0.1403(3)$ & $2.7(1)$ \\
\hline $\mathrm{CP}$ & $0.3349(2)$ & $0.0811(2)$ & $0.2225(3)$ & $3.7(2)$ \\
\hline $\mathrm{C} 10$ & $0.3606(2)$ & $0.0341(2)$ & $0.3176(3)$ & $3.9(2)$ \\
\hline C11 & $0.4312(2)$ & $0.0245(2)$ & $0.3329(3)$ & $3.4(1)$ \\
\hline $\mathrm{C} 12$ & $0.4754(2)$ & $0.0612(2)$ & $0.2512(3)$ & $3.9(2)$ \\
\hline C13 & $0.4500(2)$ & $0.1083(2)$ & $0.1564(3)$ & $3.4(1)$ \\
\hline $\mathrm{C} 14$ & $0.4029(1)$ & $0.2106(2)$ & $-0.0436(3)$ & $3.1(1)$ \\
\hline $\mathrm{C} 15$ & $0.4432(2)$ & $0.2868(2)$ & $-0.0215(4)$ & $4.2(2)$ \\
\hline C16 & $0.4887(2)$ & $0.3152(3)$ & $-0.1065(5)$ & $5.9(2)$ \\
\hline C17 & $0.4935(3)$ & $0.2698(4)$ & $-0.2123(5)$ & $6.9(3)$ \\
\hline $\mathrm{C} 18$ & $0.4542(2)$ & $0.1963(4)$ & $-0.2368(4)$ & $5.8(2)$ \\
\hline $\mathrm{C} 19$ & $0.4088(2)$ & $0.1669(2)$ & $-0.1498(3)$ & $3.7(1)$ \\
\hline $\mathrm{C} 20$ & $0.3604(2)$ & $0.0908(2)$ & $-0.1487(3)$ & $3.9(2)$ \\
\hline $\mathrm{C} 21$ & $0.3339(1)$ & $0.6109(2)$ & $-0.0054(3)$ & $2.7(1)$ \\
\hline $\mathrm{C} 22$ & $0.3603(1)$ & $0.5603(2)$ & $0.1022(3)$ & $2.6(1)$ \\
\hline $\mathrm{C} 23$ & $0.4260(2)$ & $0.5222(2)$ & $0.1004(3)$ & $3.2(1)$ \\
\hline C24 & $0.4534(2)$ & $0.4814(2)$ & $0.1988(3)$ & $3.6(1)$ \\
\hline C25 & $0.4151(2)$ & $0.4772(2)$ & $0.3012(3)$ & $3.2(1)$ \\
\hline C26 & $0.3496(2)$ & $0.5145(2)$ & $0.3042(3)$ & $3.6(2)$ \\
\hline $\mathrm{C} 27$ & $0.3229(2)$ & $0.5561(2)$ & $0.2055(3)$ & $3.3(1)$ \\
\hline C28 & $0.3396(1)$ & $0.5590(2)$ & $-0.1191(3)$ & $2.7(1)$ \\
\hline C29 & $0.3254(2)$ & $0.4664(2)$ & $-0.1211(3)$ & $3.1(1)$ \\
\hline $\mathrm{C} 30$ & $0.3281(2)$ & $0.4178(2)$ & $-0.2231(3)$ & $3.5(1)$ \\
\hline C31 & $0.3449(2)$ & $0.4604(2)$ & $-0.3271(3)$ & $3.0(1)$ \\
\hline C32 & $0.3580(2)$ & $0.5521(2)$ & $-0.3280(3)$ & $3.2(1)$ \\
\hline C33 & $0.3550(2)$ & $0.6005(2)$ & $-0.2244(3)$ & $2.9(1)$ \\
\hline C34 & $0.3655(2)$ & $0.7046(2)$ & $-0.0070(3)$ & $3.0(1)$ \\
\hline C35 & $0.4331(2)$ & $0.7309(2)$ & $-0.0254(3)$ & $3.6(1)$ \\
\hline C36 & $0.4488(2)$ & $0.8219(2)$ & $-0.0136(4)$ & $4.5(2)$ \\
\hline $\mathrm{C} 37$ & $0.3977(2)$ & $0.8838(2)$ & $0.0158(4)$ & $5.4(2)$ \\
\hline C38 & $0.3301(2)$ & $0.8584(2)$ & $0.0322(4)$ & $5.3(2)$ \\
\hline C39 & $0.3147(2)$ & $0.7667(2)$ & $0.0202(3)$ & $3.8(1)$ \\
\hline $\mathrm{C} 40$ & $0.2486(2)$ & $0.7185(2)$ & $0.0342(3)$ & $3.8(1)$ \\
\hline
\end{tabular}

$B_{\text {eq }}=(4 / 3) \Sigma_{i} \Sigma_{j} \beta_{i j} a_{i}^{*} a_{j}^{*}\left(\boldsymbol{a}_{i} \cdot \boldsymbol{a}_{j}\right)$.

ran ring (A) and two para-hydroxyphenyl rings (B and C) attached to the tetrahedral carbon atom in the fivemembered lactone ring. Each of the three moieties is almost planar. The two para-hydroxyphenyl groups lie on opposite sides of the isobenzofuran plane. The geometry differences between the two molecules are found in the orientations of the planes. The rings B and $\mathrm{C}$ are inclined with respect to each other at $71.40^{\circ}$ for Molecule 1 and $74.63^{\circ}$ for Molecule 2. The rings B and $\mathrm{C}$ are also oriented with respect to the isobenzofuran ring $A$ at $76.65^{\circ}$ and $73.63^{\circ}$, respectively, for Molecule 1 and $75.18^{\circ}$ and $70.16^{\circ}$, respectively, for Molecule 2. The $\mathrm{C}-\mathrm{O}$ bonds in the five-membered lactone rings, which cleave at alkaline $\mathrm{pH}$, are 1.490(3) and $1.484(3) \AA$, respectively, for Molecule 1 and Molecule 2. They are longer than the normal lactone C-O single bond value $(1.462(2) \AA)^{4}$ and shorter than the value of $1.525(3) \AA$ found for fluorescein. ${ }^{5}$ Fitzgerald and Gerkin ${ }^{6}$ have recently reported the crystal structure of phenolphthalein obtained from ethanol solution $(R=0.045, R w=0.097)$. Differences between the present work and the reported result were observed mainly in the molecular geometries of the lactone moieties.

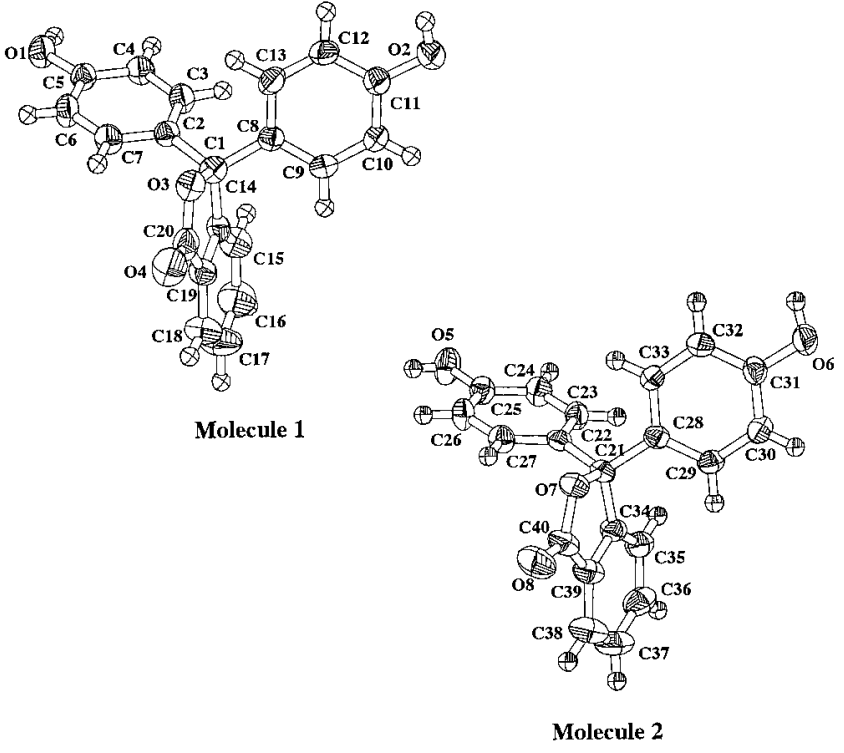

Fig. 2 Molecular structure with the numbering of the atoms. Thermal ellipsoids of the non-hydrogen atoms are scaled to enclose $50 \%$ probability. The spheres of the hydrogen atoms are drawn in an arbitrary scale.

Table 3 Selected bond lenghts ( $(\AA)$ and angles $\left({ }^{\circ}\right)$

\begin{tabular}{|c|c|c|c|c|c|c|c|}
\hline Atom & Atom & \multicolumn{2}{|c|}{ Distance } & Atom & \multicolumn{2}{|c|}{ Atom } & Distance \\
\hline$O 3$ & $\mathrm{C} 1$ & \multicolumn{2}{|c|}{$1.490(3)$} & O7 & \multicolumn{2}{|c|}{$\mathrm{C} 21$} & $1.484(3)$ \\
\hline $\mathrm{O} 3$ & $\mathrm{C} 2 \mathrm{O}$ & \multicolumn{2}{|c|}{$1.341(4)$} & O7 & \multicolumn{2}{|c|}{ C40 } & $1.343(3)$ \\
\hline O4 & $\mathrm{C} 20$ & \multicolumn{2}{|c|}{$1.216(4)$} & 08 & \multicolumn{2}{|c|}{$\mathrm{C} 40$} & $1.208(4)$ \\
\hline C19 & $\mathrm{C} 20$ & \multicolumn{2}{|c|}{$1.463(5)$} & C39 & \multicolumn{2}{|c|}{$\mathrm{C} 40$} & $1.469(5)$ \\
\hline \multicolumn{3}{|c|}{ Atom Atom Atom } & Angle & Atom A & Atom & Atom & Angle \\
\hline $\mathrm{C} 20$ & $\mathrm{O} 3$ & $\mathrm{C} 1$ & $111.3(2)$ & $\mathrm{C} 40$ & o7 & $\mathrm{C} 21$ & $111.3(2)$ \\
\hline $\mathrm{O} 3$ & $\mathrm{C} 1$ & C14 & $101.7(2)$ & O7 & C21 & C34 & $102.4(2)$ \\
\hline OB & $\mathrm{Cl}$ & $\mathrm{C} 8$ & $106.5(2)$ & O7 & $\mathrm{C} 21$ & $\mathrm{C} 28$ & $107.4(2)$ \\
\hline $\mathrm{OB}$ & $\mathrm{C} 1$ & $\mathrm{C} 2$ & $107.7(2)$ & O7 & $\mathrm{C} 21$ & $\mathrm{C} 22$ & $107.4(2)$ \\
\hline O4 & C20 & $\mathrm{O} 3$ & $121.1(3)$ & O8 & $\mathrm{C} 40$ & O7 & $120.2(3)$ \\
\hline O4 & $\mathrm{C} 20$ & C19 & $129.7(3)$ & 08 & $\mathrm{C} 40$ & C39 & $131.0(3)$ \\
\hline O3 & $\mathrm{C} 20$ & $\mathrm{C} 19$ & $109.2(3)$ & O7 & $\mathrm{C} 40$ & C39 & $108.8(3)$ \\
\hline
\end{tabular}

Estimated standard deviations in the least significant figure are given in parentheses.

\section{References}

1. K. Machida, H. Lee and T. Uno, J. Raman Spectrosc., 8, 172 (1979).

2. "TEXSAN", TEXRAY Structure Analysis Package, Molecular Structure Corporation, The Woodlands, TX, USA 1985.

3. “International Tables for X-ray Crystallography", Vol. IV, The Kynoch Press, Birmingham, 1974.

4. P. Murray-Rust, J. Murray-Rust and R. F. Newton, Acta Crystallogr., B35, 1918 (1979).

5. R. S. Osborn and D. Rogers, Acta Crystallogr., B31, 359 (1975).

6. L. J. Fitzgerald and R. E. Gerkin, Acta Crystallogr., C54, 535 (1998).

(Received January 14, 1999)

(Accepted February 24, 1999) 